\title{
Effect of different disinfecting procedures on the hardness and color stability of two maxillofacial elastomers over time
}

\author{
Panagiota N. ELENI ${ }^{1}$, Magdalini K. KROKIDA², Gregory L. POLYZOIS ${ }^{3}$, Lawrence GETTLEMAN ${ }^{4}$
}

\begin{abstract}
1- MSc, PhD, Junior Researcher, Laboratory of Process Analysis and Design, Department of Chemical Engineering, National Technical University of Athens, Zografou Campus, Athens, Greece.

2- MSc, PhD, Assistant Professor, Laboratory of Process Analysis and Design, Department of Chemical Engineering, National Technical University of Athens, Zografou Campus, Athens, Greece.

3- DDS, Dr. Dent., MScD, Associate Professor, Division of Removable Prosthodontics, Dental School, University of Athens, Athens, Greece.

4- BA, DMD, MSD, Professor of Prosthodontics \& Biomaterials, Department of Oral Health \& Rehabilitation, School of Dentistry, University of Louisville, Louisville, USA.
\end{abstract}

Corresponding address: Panagiota N. Eleni - Laboratory of Process Analysis and Design, Department of Process Analysis and Plant Design, School of Chemical Engineering, National Technical University of Athens - Zografou Campus, 15780 -Athens - Greece - Phone: 00302107723149 - Fax: 00302107723155 - e-mail: peleni@central.ntua.gr

Received: January 24, 2013 - Modified: March 21, 2013 - Accepted: May 3, 2013

\section{ABSTRACT}

O bjective: Disinfection procedures often cause deterioration in a maxillofacial prosthesis. Color and hardness alterations could lead to a replacement of the prosthesis. Material and Methods: An experimental chlorinated polyethylene (CPE) and a commercial polydimethyl siloxane (PDMS) sample were treated with four different disinfection procedures for a period which simulates 1 year of clinical service. The applied disinfection procedures included microwave exposure and immersion in three solutions, sodium hypochlorite, neutral soap and a commercial disinfecting soap. Shore $A$ hardness $(\Delta \mathrm{H})$ and color differences $(\Delta \mathrm{E})$ were determined before and after each procedure. All data were analyzed by Two Way Analysis of Variance (ANOVA) and Tukey's post hoc tests at a level of $\alpha=0.05$. Results: The samples presented significant alterations in color and hardness after the different disinfection treatments. The color differences $(\Delta \mathrm{E})$ were at least eye detectable in all cases and clinically unacceptable in most of the cases, with values ranging from 1.51 to 4.15 and from 1.54 to 5.92 for the PDMS and CPE material, respectively. Hardness was decreased after all the disinfection procedures in the PDMS, while for the CPE, a decrement was observed after disinfection with sodium hypochlorite and neutral soap and an increment after microwave exposure and the disinfection with a commercial antimicrobial agent. The PDMS samples presented greater alterations in color and hardness after disinfection with sodium hypochlorite solution, while the microwave exposure caused negligible effects. The CPE samples were affected most after disinfection when treated with neutral soap, and more slightly when disinfected with sodium hypochlorite solution. Conclusions: The disinfection procedures caused alterations in color and hardness of the examined materials. The most suitable disinfection procedure for the PDMS material is microwave exposure, while disinfection with sodium hypochlorite solution is not recommended. The CPE material is suggested to be disinfected with sodium hypochlorite solution and the use of neutral soap is not recommended. Comparing the two materials, the PDMS material is most color stable, while the CPE material presented fewer changes in hardness.

Key words: Color. Hardness. Maxillofacial prosthesis. Elastomers. Microwaves. Sodium hypochlorite. 


\section{INTRODUCTION}

A maxillofacial prosthesis has been an adequate solution for patients who present malformations in the region of the face and maxilla, mainly due to trauma, disease or congenital deformities ${ }^{20}$. Although maxillofacial prosthetic materials have been improved over the last decades in order to better simulate the replacing tissue and provide greater comfort to patients, it still experiences some problems ${ }^{1}$. The main disadvantage is that the prosthesis has to be replaced almost every 1-1.5 years, depending on the material used and the type of the prosthesis, mainly due to the discoloration that it undergoes ${ }^{16}$.

Maxillofacial elastomers undergo significant alterations in their structure and appearance during the life service mainly due to aging caused by the exposure in climate conditions, such as solar irradiation, temperature, humidity, etc ${ }^{28}$. Many studies have reported these changes after performing accelerated aging exposure ${ }^{3,6}$ and solar exposure experiments ${ }^{4,28}$. Moreover, significant changes also occurred due to skin secretions ${ }^{27}$ and different disinfection treatments ${ }^{6-9,33}$. Patients have to disinfect their maxillofacial prosthesis every day in order to maintain their hygiene. Different commercially available solutions and others such as hypochlorite cleansers or neutral soaps $^{7}$ are available and each one is suitable for different types of elastomers ${ }^{2,12}$. Whichever solution is chosen, disinfection should be a daily treatment lasting 3-5 minutes, in which patients have to apply them on the prosthesis and wipe it out gently without brushing ${ }^{12,13}$ in order to avoid dissolving and removing some pigments from the external surface ${ }^{30}$. Sodium hypochlorite solutions have been mainly used in denture base and denture lining materials and rarely in maxillofacial elastomers due to the alterations caused in their physical properties 2,32 . However, since no detrimental effect of sodium hypochlorite solutions have occurred in denture base and denture lining materials, especially when using solutions in low concentrations of hypochlorite, it is well worth it to be applied in maxillofacial elastomers ${ }^{5,32}$. Moreover, microwave exposure as a disinfecting treatment which has been used in dentistry ${ }^{17,31}$, has been applied in maxillofacial elastomers ${ }^{20}$.

As mentioned, maxillofacial elastomers during their clinical life reveal changes, which affect their structure and surface characteristics. Although, alterations in the structure of a polymer affect its mechanical and thermal characteristics, surface changes are also important. Color and surface changes, such as hardness, are often the main reasons for replacing a prosthesis since these are the alterations that patients usually perceive and are eye detectable ${ }^{8-10,19}$.

The aim of this study was to examine the effect of four different disinfection procedures on the color and hardness of two maxillofacial elastomers. The selected elastomers were a commercial polydimethyl siloxane (PDMS) and an experimental chlorinated polyethylene (CPE). The null hypothesis tested was that the detected differences in hardness and color were not affected by the disinfection procedures and the examined materials.

\section{MATERIAL AND METHODS}

\section{Material}

A medical grade polydimethyl siloxane (PDMS) and a chlorinated polyethylene (CPE) have been selected and studied, as presented in Figure 1 . The PDMS specimens were cured at $100^{\circ} \mathrm{C}$ in gypsum molds for 2 hours, while the CPE samples were cured in gypsum molds at $110^{\circ} \mathrm{C}$ and offered by the University of Louisville. From each material 20 rectangular specimens $(15 \times 20 \times 35 \mathrm{~mm}), 5$ for each disinfection procedure were fabricated.

\section{Disinfecting procedures}

For the disinfection of the CPE and PDMS samples, four different disinfecting procedures were selected (Figure 2). Measurements were carried out before and after each disinfection procedure. The samples before each disinfecting procedure were considered as self- controls.

Microwave Exposure (DP1): The microwave exposure was accomplished by using an unmodified domestic oven with a rotating table. An exposure of 3 minutes and energy of 650 Watts was used ${ }^{22}$ 365 times. Samples were immersed in tap water (200 mL) which was replenished for each run ${ }^{20}$, simulating 1 year of service with 3 minutes daily treatment.

Hypochlorite solution (DP2): Five samples of each material were immersed for 30 hours in the hypochlorite solution. Sodium hypochlorite

\begin{tabular}{|c|c|c|c|}
\hline Materia & Coding & Type & Manufacturer \\
\hline PDMS & A & Multisil Epithetik /Commercial addition curing & Bredent GmbH, Senden, Germany \\
\hline CPE & B & Experimental Chlorinated Polyethylene & $\begin{array}{c}\text { Department of Oral Health \& Rehabilitation, } \\
\text { School of Dentistry, University of Louisville (501 S. } \\
\text { Preston St, Louisville, KY 40202-1701 USA) }\end{array}$ \\
\hline
\end{tabular}

Figure 1- Maxillofacial elastomers studied 
solution $(1 \% \mathrm{w} / \mathrm{w})$ was prepared by diluting $1 \mathrm{~L}$ of a commercial chlorine product (Klinex, Unilever Hellas S.A., Greece, 4.8\% w/w Sodium Hypochlorite) in 4.2 L distilled water. The examined period simulated approximately one year, because 30 hours is 360 days of service for a 5 minute daily treatment ${ }^{5}$.

Neutral soap (DP3): Samples were immersed in neutral soap for a period of 30 hours, which approximately simulates 1 year of service because 30 hours is 360 days concerning a 5 minute daily treatment ${ }^{9}$.

Commercial disinfecting solution (DP4): A commercial antimicrobial agent was selected for the disinfection of the maxillofacial prostheses. Samples were immersed in DP4 solution for 30 hours to simulate 1 year of (30 hours is 360 days) service assuming a 5 minute daily treatment ${ }^{12,13}$.

\section{Hardness test}

Samples were tested before and after the disinfection procedures using a CV-DSAS digital (durometer) Shore A tester (CV-DSAS, CV Instruments Europe BV, Maastricht, The Netherlands), model CV-DSAS001, in conjunction with a bench stand (providing a weight of $1 \mathrm{~kg}$ during $15 \mathrm{~s}$ ). This method is based on the penetration of a needle on the surface of the material with a constant load. The results from six readings taken at six different positions in the surface ( $6 \mathrm{~mm}$ apart) for each specimen were averaged. The absolute

\begin{tabular}{|c|c|c|c|}
\hline Disinfection procedures & Procedure duration & $\begin{array}{c}\text { Simulated years } \\
\text { of service }\end{array}$ & Coding \\
\hline $\begin{array}{c}\text { Microwave exposure } \\
\text { (Panasonic, Model: NN 5256B, 2450 MHz, Matsushita } \\
\text { Electric Industrial Co. Ltd., Osaka, Japan). }\end{array}$ & 365 times 3 min & DP1 & \\
\hline Sodium hypochlorite solution (1\% w/w) & 30 hours & 1 year & DP2 \\
\hline $\begin{array}{c}\text { Neutral soap } \\
\text { (Ns -Johnson \& Johnson, GmbH, Italy) }\end{array}$ & 30 hours & DP3 year \\
\hline $\begin{array}{c}\text { Commercial disinfecting solution (Daro B-200-09, } \\
\text { Technovent Ltd., South Wales, UK) }\end{array}$ & 30 hours & 1 year & DP4 \\
\hline
\end{tabular}

Figure 2- Disinfection procedures applied

Table 1- Two-way analysis of variance results for $\Delta \mathrm{H}$ and $\Delta \mathrm{E}$ measurements

\begin{tabular}{|c|c|c|c|c|c|c|}
\hline Source & & Sum of Squares & df & $\begin{array}{c}\text { Mean } \\
\text { Square }\end{array}$ & $\mathbf{F}$ & Sig. \\
\hline \multirow[t]{2}{*}{ Disinfection procedures } & $\Delta \mathrm{H}$ & 0.691 & 3 & 0.230 & 1.789 & 0.169 \\
\hline & $\Delta \mathrm{E}$ & 37.67 & 3 & 12.559 & 40.143 & 0.000 \\
\hline \multirow[t]{2}{*}{ Material } & $\Delta \mathrm{H}$ & 1.757 & 1 & 1.757 & 13.651 & 0.001 \\
\hline & $\Delta \mathrm{E}$ & 4.536 & 1 & 4.536 & 14.498 & 0.001 \\
\hline \multirow[t]{2}{*}{ Interaction (Disinfection Procedure*Material) } & $\Delta \mathrm{H}$ & 1.428 & 3 & 0.476 & 3.697 & 0.022 \\
\hline & $\Delta \mathrm{E}$ & 38.255 & 3 & 12.752 & 40.758 & 0.000 \\
\hline \multirow[t]{2}{*}{ Error } & $\Delta \mathrm{H}$ & 4.119 & 32 & 0.129 & & \\
\hline & $\Delta \mathrm{E}$ & 10.012 & 32 & 0.313 & & \\
\hline
\end{tabular}

Table 2- $\Delta \mathrm{E}$ mean values and standard deviations for material $\mathrm{A}$ and $\mathrm{B}$ after the different disinfection procedures and Tukey's multiple comparisons results, $(n=40)$

\begin{tabular}{ccc}
\hline Disinfection procedures & Material A & Material B \\
\hline DP1 & $\boldsymbol{\Delta}$ & $\boldsymbol{\Delta}$ \\
\hline DP2 & $1.51^{\mathrm{a}} \pm 0.65$ & $3.54^{\mathrm{c}} \pm 0.71$ \\
DP3 & $4.15^{\mathrm{a}} \pm 0.26$ & $1.54^{\mathrm{d}} \pm 0.15$ \\
DP4 & $3.64^{\mathrm{b}} \pm 0.47$ & $5.92^{\mathrm{e}} \pm 0.72$ \\
\hline
\end{tabular}

${ }^{*} a, b, c, d$, e: Means with the same letter in columns for respective type of disinfection procedure are not significantly different ( $p>0.05)$. Values reported are an average of 5 specimens 
differences in hardness $(\Delta H)$ were then calculated using the measured values before and after each procedure for each sample.

\section{Evaluation of color}

Color changes were evaluated using a MiniScan XE Spectrophotometer (Hunter Associates Laboratory Inc, Reston, Virginia, United States), with a measuring head aperture of $4 \mathrm{~mm}$ in diameter. The spectrophotometer was calibrated according to the manufacturer instructions, using the supplied black and white calibration standard. Values were carried out according to the CIELAB color system. The CIELAB system uses the three dimensionless colorimetric parameters $L, a, b$ whereby $L$ indicates the brightness, a describes the red-green content and $b$ the yellow-blue content ${ }^{18}$. The samples were able to serve as controls, since they were not damaged or otherwise affected by the measurements and could be measured before and after the disinfection procedures ${ }^{14,15,29}$. Three readings were taken for each sample, and the mean

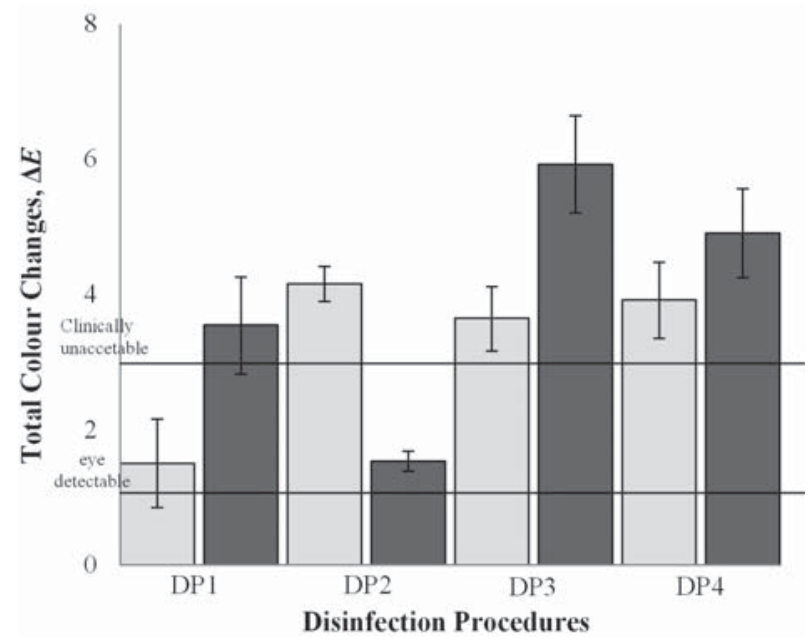

Figure 3- Mean values of total color differences and standard deviations for samples A (grey columns) and B (black columns) after the four different disinfected procedures

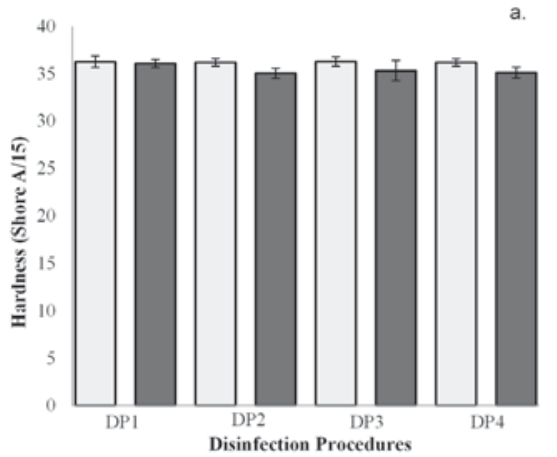

values were automatically calculated and recorded by the colorimeter.

Color difference $(\Delta E)$ was calculated according to equation 1 .

$$
\Delta E=\sqrt{(\Delta L)^{2}+(\Delta a)^{2}+(\Delta b)^{2}}
$$

Where $\Delta L, \Delta a$ and $\Delta b$ are changes in $L, a$ and $b$, respectively, in the samples before and after the disinfection procedures, and $\Delta \mathrm{E}$ indicates the total color difference.

\section{Statistical analysis}

Hardness and color differences were first evaluated for the homogeneity of variances by the Levene's test and Kolmogorov-Smirnov test for normality. Two-way analysis of variance (ANOVA) and Tukey's tests were applied to detect differences among all the groups. Analyses were performed with the SPSS for Windows software (SPSS 16.0, SPSS Inc, Chicago, III.). A significance level of $\alpha=.05$ was selected.

\section{RESULTS}

Statistical analyses, for color and hardness differences, are presented in Table 1. Table 2 shows the mean values, standard deviations and Tukey's post hoc results among the different materials and procedures.

Figure 2 presented the mean values and standard deviations of the total color differences, $\Delta E$, for materials $A$ and $B$. The figures also presented the thresholds between the eye detectable and clinically unacceptable values. In a previous study, perceptibility and acceptability thresholds, color differences in light and dark skin-colored maxillofacial elastomers had been determined. For the fair specimens, perceptibility/acceptability thresholds were considered equal to 1.1/2.1 and 1.6/4.4 for the dark specimens ${ }^{25}$. Different values were presented by Han, et al. ${ }^{14}$ (2010), concerning color changes in the maxillofacial elastomers with and without pigments, equal to 1.1 and 3 for perceptibility and acceptability thresholds,

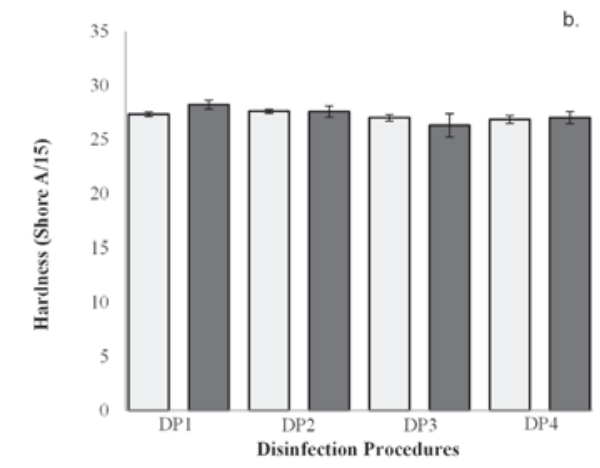

Figure 4- Mean values of hardness measurements and standard deviation before (grey columns) and after (black columns) each disinfection procedure for material a. A and b. B 
respectively ${ }^{11}$. Since the examined materials were non-pigmented in the present study, color changes greater than 1.1 were considered as eye detectable and greater or equal to 3 as clinically unacceptable.

Figures $4 a$ and $4 b$, presented the measured hardness values for materials $A$ and $B$, respectively, before and after each disinfection procedure. For material A, all disinfection procedures caused a decrement in the samples' hardness, while for material B, disinfection procedures DP1 and DP4 caused an increment and DP2 and DP3 a decrement.

\section{DISCUSSION}

It is obvious that the null hypothesis was partly rejected since the color and hardness changes presented differences among the materials, but only material B presented changes among the different disinfection procedures. Our results revealed significant differences in the studied properties between the two materials but also among the disinfection procedures, at least for the color changes. Even if the hardness alterations didn't statistically differ through the four treatments, some conclusions can be drawn. More specifically, for material A, sodium hypochlorite solution (DP2) most affected its color and hardness, while the lowest differences were presented after microwave exposure (DP1). For material B, the sodium hypochlorite solution (DP2) caused the smallest changes while the neutral soap (DP3) affected it most.

Comparing the two materials, it could be observed that material A presents the highest hardness alterations but is most color stable. Moreover, as presented in Figure 1, color changes in all cases were at least eye detectable. In addition, except for material $A$ after treatment with DP1 and for material B with DP2, which were the procedures that affected them less, the materials after all the other procedures presented clinically unacceptable color changes. The hardness values of the maxillofacial elastomers should remain between a specific range for their clinical application. The appropriate range is wide (approximately 10-45 Shore A) and depending on the replacing facial region since the facial area varies in hardness and stiffness ${ }^{21}$. Considering this range, all the changes in the hardness values of the examined materials could be characterized as clinically acceptable.

The observed changes in color and hardness could be associated with the surface characteristics of the polymers along with the extraction of some compounds from the polymer matrix to disinfection solutions or the water ${ }^{9,26}$. Mancuso, et al. ${ }^{23}$ (2009) reported that extrinsic factors, such as the absorption and adsorption of substances, causes discoloration. Goiato, et al. ${ }^{12}$ (2009) reported that the chemical cleansing agents could cause damage to the material's physical properties, such as an increase in absorption and solubility. Especially when the samples are immersed in hypochlorite solution during the disinfection procedure, a porous structure may have formed and according to Mancuso, et al. ${ }^{24}$ (2009), the additives to the silicone materials may promote water absorption and lead to reduced hardness ${ }^{6}$, as it was observed for material A after disinfection with hypochlorite solution. Moreover, alterations in the hardness values could be probably due to continuous polymerization of the elastomer, which causes not only a dimensional alteration of the elastomers, but also alterations in their chromatic pattern ${ }^{6,9}$.

Microwave exposure has been found to increased hardness, since thermal cycling, which also occurred during exposure, increased the hardness of the specimens and works against the effect of water uptake that would normally cause softening ${ }^{22}$, as it was observed in material B. Moreover, the color changes presented in both materials after the microwave exposure was in line with a previous study of Kiat-amnuay, et al.20 (2005), in which color changes were reported in a maxillofacial silicone elastomer, with and without pigmentation, after applying similar conditions.

Materials after disinfection with the antimicrobial cleaning solution (DP4) presented either a decrease, as was observed in material A, or an increase, as in material $B$, in their hardness. This is maybe caused due to the decomposition of the cleaning solution into carbon monoxide, carbon dioxide, and sulfur dioxide as reported by Hatamleh, et al. ${ }^{12}$ (2011). Significant color changes were also reported in another study after using the same antimicrobial cleaning solution (DP4) in maxillofacial silicone elastomers, with and without pigmentation ${ }^{13}$, as it was also presented in our results.

Goiato, et al. ${ }^{9}$ (2009) reported that the choice of a chemical agent for a prosthesis cleansing should be based not only on its antimicrobial properties, but also its compatibility, in order to preserve as much as possible the physical properties of the surface of the materials.

\section{CONCLUSIONS}

Within the limitations of this study, we can conclude that: (1) The most suitable disinfection procedure for the PDMS material is microwave exposure, while, disinfection with sodium hypochlorite solution is not recommended. (2) The CPE material is suggested to be disinfected with sodium hypochlorite solution and the use of neutral soap is not recommended. (3) The PDMS material is most color stable, while the CPE material presented the least change in hardness. 


\section{CONFLICT OF INTEREST}

The authors declare that they have no conflict of interest.

\section{ACKNOWLEDGMENTS}

Our thanks are extended to Vitsaropoulos M S.A for providing Multisil prosthetic elastomer.

\section{REFERENCES}

1- Aziz T, Waters M, Jagger R. Analysis of the properties of silicone rubber maxillofacial prosthetic materials. J Dent. 2003;31:67-74. 2- Budtz-Jørgensen E. Materials and methods for cleaning dentures. J Prosthet Dent. 1979;42:619-23.

3- Eleni PN, Krokida MK, Polyzois GL. The effect of artificial accelerated weathering on the mechanical properties of maxillofacial polymers PDMS and CPE. Biomed Mater. 2009;4:035001.

4- Eleni PN, Krokida MK, Polyzois GL, Charitidis CA, Koumoulos EP, Tsikourkitoudi VP, et al. Mechanical behaviour of a poydimethylsiloxane elastomer after outdoor weathering in two different weathering locations. Polym Degrad Stab. 2011;96:4706.

5- Ferreira M, Pereira-Cenci T, Rodrigues de Vasconcelos L, Rodrigues-Garcia R, Del Bel Cury AA. Efficacy of denture cleansers on denture liners contaminated with Candida species. Clin Oral Investig. 2009;13:237-42.

6- Goiato MC, Haddad MF, Santos DM, Pesqueira AA, Moreno A. Hardness evaluation of prosthetic silicones containing opacifiers following chemical disinfection and accelerated aging. Braz Oral Res. 2010;24:303-8.

7- Goiato MC, Haddad MF, Sinhoreti MA, Santos DM, Pesqueira $A A$, Moreno $A$. Influence of opacifiers on dimensional stability and detail reproduction of maxillofacial silicone elastomer. Biomed Eng Online. 2010;9:85.

8- Goiato MC, Pesqueira AA, Santos DM, Dekon SF. Evaluation of hardness and surface roughness of two maxillofacial silicones following disinfection. Braz Oral Res. 2009;23:49-53.

9- Goiato MC, Pesqueira AA, Santos DM, Zavanelli AC, Ribeiro PP. Color stability comparison of silicone facial prostheses following disinfection. J Prosthodont. 2009;18:242-4.

10- Guiotti AM, Goiato MC, Santos DM. Evaluation of the Shore A hardness of silicone for facial prosthesis as to the effect of storage period and chemical disinfection. J Craniofac Surg. 2010;21:323-7. 11- Han Y, Zhao Y, Xie C, Powers JM, Kiat-amnuay S. Color stability of pigmented maxillofacial silicone elastomer: effects of nanooxides as opacifiers. J Dent. 2010;38(Suppl 2):e100-5.

12- Hatamleh MM, Polyzois GL, Silikas N, Watts DC. Effect of extraoral aging conditions on mechanical properties of maxillofacial silicone elastomer. J Prosthodont. 2011;20:439-46.

13- Hatamleh MM, Watts DC. Effect of extraoral aging conditions on color stability of maxillofacial silicone elastomer. J Prosthodont. 2010;19:536-43.

14- Hatamleh MM, Watts DC. Porosity and color of maxillofacial silicone elastomer. J Prosthodont. 2011;20:60-6.

15- Haug SP, Andres CJ, Moore BK. Color stability and colorant effect on maxillofacial elastomers. Part III: weathering effect on color. J Prosthet Dent. 1999;81:431-8.
16- Hooper SM, Westcott TP, Evans LL, Bocca AP, Jagger DC. Implant-supported facial prostheses provided by a maxillofacial unit in a U.K. regional hospital: longevity and patient opinions. J Prosthodont. 2005;14:32-8.

17- Hume WR, Makinson OF. Sterilizing dental instruments: evaluation of lubricating oils and microwave radiation. Oper Dent. 1978;3:93-6.

18- Johnston WM, Kao EC. Assessment of appearance match by visual observation and clinical colorimetry. J Dent Res. 1989;68:819-22.

19- Keyf F. Change in a maxillo-facial prosthesis material effected from environmental factors: a clinical report. J Biomater Appl. 2002;16:259-66.

20- Kiat-amnuay S, Johnston DA, Powers JM, Jacob RF. Color stability of dry earth pigmented maxillofacial silicone A-2186 subjected to microwave energy exposure. J Prosthodont. 2005; 14:91-6.

21- Lewis DH, Castleberry DJ. An assessment of recent advances in external maxillofacial materials. J Prosthet Dent. 1980;43:426-32. 22- Machado AL, Breeding LC, Puckett AD. Effect of microwave disinfection on the hardness and adhesion of two resilient liners. J Prosthet Dent. 2005;94:183-9.

23- Mancuso DN, Goiato MC, Santos DM. Color stability after accelerated aging of two silicones, pigmented or not, for use in facial prostheses. Braz Oral Res. 2009;23:144-8.

24- Mancuso DN, Goiato MC, Zuccolotti BC, Moreno A, Santos DM. Evaluation of hardness and colour change of soft liners after accelerated ageing. Prim Dent Care. 2009;16:127-30.

25- Paravina RD, Majkic G, Del Mar Perez M, Kiat-amnuay S. Color difference thresholds of maxillofacial skin replications. J Prosthodont. 2009;21:133-9.

26- Pesqueira AA, Goiato MC, Santos DM, Haddad MF, Ribeiro PP, Coelho Sinhoreti MA, et al. Effect of disinfection and accelerated aging on color stability of colorless and pigmented facial silicone. J Prosthodont. 2011;20;305-9.

27- Polyzois GL, Tarantili PA, Frangou MJ, Andreopoulos AG. Physical properties of a silicone prosthetic elastomer stored in simulated skin secretions. J Prosthet Dent. 2000;83:572-7.

28- Sampers J. Importance of weathering factors other than UV radiation and temperature in outdoor exposure. Polym Degrad Stab. 2002;76:455-65.

29- Santos DM, Goiato MC, Moreno A, Pesqueira AA, Haddad MF. Influence of pigments and opacifiers on color stability of an artificially aged facial silicone. J Prosthodont. 2011;20:205-8. 30- Shi Y, Song W, Feng Z, Zhao Y, Li F, Tian Y, et al. Disinfection of maxillofacial silicone elastomer using a novel antimicrobial agent: recombinant human beta-defensin-3. Eur J Clin Microbiol Infect Dis. 2009;28:415-20.

31- Webb BC, Thomas CJ, Harty DW, Willcox MD. Effectiveness of two methods of denture sterilization. J Oral Rehabil. 1998;25:41623.

32- Webb BC, Thomas CJ, Willcox MD, Harty DW, Knox KW. Candida-associated denture stomatitis. Aetiology and management: a review. Part 2. Oral diseases caused by Candida species. Aust Dent J. 1998;43:160-6.

33- Yilmaz H, Aydin C, Gul B, Yilmaz C, Semiz M. Effect of disinfection on the dimensional stability of polyether impression materials. J Prosthodont. 2007;16:473-9. 